\title{
Easiness, usefulness and intention to use a MOOC in nursing
}

\author{
José Miguel Padilha a,b,*, Paulo Puga Machado ${ }^{\mathrm{a}, \mathrm{c}}$, Ana Leonor Ribeiro ${ }^{\mathrm{a}, \mathrm{c}}$, Rui Ribeiro ${ }^{\mathrm{d}}$, \\ Francisco Vieira ${ }^{\mathrm{a}, \mathrm{e}}$, Patrício Costa ${ }^{\mathrm{f}, \mathrm{g}, \mathrm{h}}$

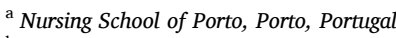 \\ ${ }^{\mathrm{b}}$ CINTESIS - Tech4edusim (Center for Health Technology and Services Research, Faculty of Medicine, University of Porto), Porto, Portugal \\ ${ }^{\mathrm{c}}$ CINTESIS - NursID (Center for Health Technology and Services Research, Faculty of Medicine, University of Porto), Porto, Portugal \\ ${ }^{\mathrm{d}}$ Unidade para a Computação Científica Nacional - Fundação para a Ciência e a Tecnologia, Portugal \\ e IMP Research Group \\ ${ }^{\mathrm{f}}$ Life and Health Sciences Research Institute (ICVS), School of Medicine, University of Minho, Braga, Portugal \\ ${ }^{\mathrm{g}}$ ICVS/3B's, PT Government Associate Laboratory, Braga, Guimarães, Portugal \\ ${ }^{\mathrm{h}}$ Faculty of Psychology and Educational Sciences, University of Porto, Portugal
}

\section{A R T I C L E I N F O}

\section{Keywords:}

Pulmonary disease, chronic obstructive

Education, nursing

MOOC

Self-management

Education, distance

\begin{abstract}
A B S T R A C T
Background: The growing ageing population and the increasing prevalence of non-communicable diseases call for innovation and healthcare mastered professional skills. Emerging digital learning contents envisioning to complement education, lifelong learning and in-service training. The use of digital platforms allows nurses to access contents in several formats, enabling the required pedagogical autonomy and personal time management. This allows nurses to enrol in education wherever accessible, reducing personal and professional costs and ensuring high-quality standards.

Objectives: To assess students and nurses' easiness, usefulness and intention to use a Massive Open Online Course (MOOC) as an educational resource to enhance self-management intervention skills in COPD patients. Methods: An exploratory, descriptive and transversal study was conducted. Participants were nursing students, registered nurses and rehabilitation nurses. A questionnaire supported by Davis Technology Acceptance Model and on the determinants of the ease-of-use perception of Venkatesh was applied. An EFA was performed and two dimensions were obtained (perceived easiness and global quality of the course and perceived usefulness and intention to use the MOOC) and groups were compared in these dimensions.

Results: From the total participants $(n=93), 65.6 \%$ were nursing students, $15.1 \%$ were Portuguese nurses and $19.4 \%$ were Portuguese rehabilitation nurses. The perceived easiness and global quality score of the course were $4.70(\mathrm{SD}=0.314)$ and the perceived usefulness and intention to use the MOOC was $4.73(\mathrm{SD}=0.346)$. Rehabilitation nurses, who are older, scored higher than nurses and students $\left(\chi^{2}(2, n=93)=8.43, p=.015, \varepsilon^{2}=\right.$ 0.092). The dropout rate was $25 \%$.

Conclusions: The MOOC showed usefulness and nurses' intention to use this educational resource in future education and yielded high average rates of perceived easiness and global quality.

These massive courses unlock new opportunities for nursing education and to lifelong learning in nursing, enhancing safety and quality of the healthcare services in supporting patients to achieve a better quality of life.
\end{abstract}

\section{Background}

The United Nations blueprint seeks to achieve a better and more sustainable future for all by 2030 . In this sense sustainable development goals (SDG) fit in the strengthening of initial and continuing training of healthcare professionals (SDG 4) by integrating technological innovation into education (SDG 9), contributing to the improvement of the quality of life of the overall population (SDG 3) (United Nations, 2015). These SDG demands new pedagogical approaches to healthcare professionals' lifelong learning education.

Society is facing new and demanding challenges posed by the growing ageing population and subsequent increase of noncommunicable diseases (NCDs) (WHO, 2019a). The five most prevalent NCD'S are heart disease, stroke, cancer, diabetes and chronic lung

\footnotetext{
* Corresponding author at: Escola Superior de Enfermagem do Porto, Street Dr. António Bernardino de Almeida, 4200-072 Porto, Portugal.

E-mail address: miguelpadilha@esenf.pt (J.M. Padilha).
} 
disease and these are responsible for almost $70 \%$ of all deaths worldwide (WHO, 2019a). In Europe region deaths by these NCD'S reach to $86 \%$ (WHO, 2019b).

The growing ageing population and the increasing prevalence of NCDs challenge healthcare systems and professionals to develop new strategies to reduce mortality, morbidity and enhance the quality of life of patients with NCDs and ensure healthcare systems sustainability. These challenges call for innovation in healthcare services and mastered skills of healthcare professionals.

Lifelong learning is one of the strategies available and widely used by healthcare professionals to keep up-to-date. Lifelong learning was traditionally adopted by in-service training, universities or educational institutions. The 21st-century demands in healthcare prompt these professionals certification and up-to-date in the practice core fields as a way to ensure the safety and quality of the healthcare provided. The access to a certified high-quality lifelong learning digital education in a globalization era responds to time and financial constraints as well as familiar management challenges.

Emerging digital learning contents for healthcare professionals envisioning to complement rather than replaces traditional methods of delivering continued health education and in-service training (WHO, 2019c).

Nowadays the massive use of Information and Communications Technology (ICT) and high technological literacy of young generations of healthcare providers contribute to the perceived usefulness and intention to adopt new pedagogical approaches aiming to facilitate learning in undergraduate students and lifelong learning education (Padilha et al., 2018).

The use of digital platforms allows students and healthcare professionals to access contents in several formats, such as asynchronous layouts, enabling the required pedagogical autonomy and personal time management. The complementary use of this strategy and interactive technologies of discussion fosters active learning.

In the 21 st century, the teaching/learning methodologies focused on exposure, repetition and memorization are no longer challenging and incite the development of innovative teaching/learning methods using ICT tools. The attention is focused on the development of strategies targeted at active learning, in which the teacher is both a promoter and a facilitator of the learning process, helping healthcare professionals to learn from experiences and contextualized environments, thus meeting personal expectations and boosting motivation to learn (AlRuthia et al., 2019; Woods and Rosenberg, 2016; Scott et al., 2014; Hoke and Robbins, 2005).

In the nursing area, e-learning (as a strategy for the dematerialization of education) provides a wide scope of advantages but also raises some challenges. In fact, evidence shows that in the acquisition of basic skills in nursing the outcomes using e-learning strategies are similar to those achieved using conventional methodologies (Voutilainen et al., 2017; Lahti et al., 2014). In the healthcare field, the comparison between traditional learning and e-learning shows little or no difference in the improvement of patient outcomes or health professionals' behaviour or knowledge. The evidence is uncertain whether e-learning improves or reduces health professionals' skills and shows that e-learning strategies are not better or worse than traditional education (Vaona et al., 2018). Despite this context and the paradox between traditional and e-learning education, the path of a more customized lifelong education is unquestionable. This opens a new opportunity to overtake some of the challenges faced by healthcare professionals to access education through easing the usage and enrolment wherever education is accessible, reducing personal and professional costs and assuring high-quality standards. Also, e-learning allows educational reference institutions to broaden their horizons offering services to larger audiences.

Moreover, the World Health Organization (WHO) recommends the digital provision of training and educational content for health workers, via mobile devices/mLearning as a complement of continued health education and in-service training (WHO, 2019c). Nowadays, the main question should not address the most effective pedagogical strategy but explore the easiness of access to high-quality standards in education, to support healthcare providers in keeping up-to-date skills and to guarantee quality and safety of healthcare services.

\subsection{Massive Open Online Courses}

One of the most prolific and disseminated types of distance education, the Massive Open Online Courses (MOOC) emerged in 2008 (Cormier, 2008). Since then, we have been witnessing the evolution of theoretical models to support MOOC, evolving from connectivist theories - knowledge and learning as a result of the networking of relationships - to behaviourist theories approaches - emphasizing content prepared by reference educational institutions and user satisfaction and engagement motivation. However, independently of the growing number of available MOOCs, today it is not possible to identify a structural model to measure the success of MOOC (Aparicio et al., 2019). In fact, the high dropout rate commonly found in MOOC poses serious questions about their usefulness and viability (Aydin, 2018; Jordan, 2014). To overcome this gap, strategies based on enhancing participant's internal and external motivation became one of the major challenges to MOOC developers.

Over the past years, gamified environments have been introduced in MOOCs, viewed as a differentiated feature that increases users' motivation and rates completion (Khalil et al., 2018; Buckley and Doyle, 2014; Guillén-Nieto and Aleson-Carbonell, 2012). The gamified learning environments are using game elements to increase enjoyability and challenge and may include playful and ludic elements evolving, in health-related contents, to interact with virtual patients (Berman et al., 2017). The use of gamified environments and serious games effectively increases motivation and participation of MOOC students (Aparicio et al., 2019; Gentry et al., 2018; Buckley and Doyle, 2014; Chau et al., 2013; Guillén-Nieto and Aleson-Carbonell, 2012).

Thus, gamification construction is highlighted as the most important driver on MOOC use, with strong individual and organizational impact and likely to influence the way users perceive individual progress and usefulness of the course and its learning goals (Looyestyn et al., 2017). The evidence also shows that the quality of information directly influences satisfaction (Albelbisi, 2019; Yang et al., 2017).

To develop new approaches with high-quality standards in MOOCs, gamified environments should be embedded with clinical virtual simulation scenarios. Clinical virtual simulation supports the development of clinical decision competencies of healthcare providers and increases user satisfaction (Padilha et al., 2019), encouraging the user to play an active role and highlighting the user's competencies progress throughout the learning experience.

Clinical Virtual Simulation (CVS) technologies can help refocus the healthcare professionals learning process within a quasi-real clinical scenario through the optimization of the learning conditions (Padilha et al., 2019). The main goal is not to replace clinical experience or internship but rather prepare the healthcare professionals to engage in future real clinical scenarios and help them anticipate intervention needs to ensure safety and quality in healthcare delivery. Thus, gamified learning environments using CVS in health education offer a wide variety of opportunities for learning processes namely the improvement of knowledge retention, professional skills, satisfaction, critical thinking, decision-making and self-confidence (Rosa, 2018; Marques, 2018; Padilha et al., 2019).

\subsection{Nurses challenges to keep up-to-date with the management of NCD}

The increasing number of nursing professionals in healthcare systems and their continuously demanding role is mostly affected by the clinical burden in supporting patients with NCD aiming to provide and promote better disease control and quality of life.

One of the most prevalent chronic respiratory diseases is Chronic 
Obstructive Pulmonary Disease (COPD). COPD is one of the major causes of mortality and disability and by 2020 , it is expected to be the third cause of death worldwide. The global death toll of people with COPD has reached more than 3 million (GOLD, 2020).

The COPD burden in the individual, society, economy, health and social security systems have urged the identification and implementation of strategies by international entities such as the Global Initiative for Chronic Obstructive Lung Disease (GOLD, 2020). Despite the success in implementing these strategies, the majority focus on the health system and health professionals' response. However, COPD as a chronic disease, implies active participation and engagement of the patient in the self-management of the disease.

In the last decade, much has been done for the prevention, diagnosis and management enhancement, however, more attention must be paid to patients' behaviour and skills to cope with the disease. This involves supporting patients to play an active role in the disease management enhancing their skills to help them achieve better functionality and quality of life (Padilha, 2013; Zwerink et al., 2014). GOLD (2020) stresses that self-management intervention aims to motivate, engage and coach patients to positively adapt their health behaviour(s) and develop skills to better manage their disease daily.

The self-management intervention implementation requires the development of patient-centred interactions between patients and expert healthcare professionals in delivering self-management interventions.

In the healthcare systems, nurses play a key role in supporting the development of self-management skills of COPD patients, meaning that nurses have to keep up-to-date with COPD global management.

Today, the challenge is on how to develop a pedagogical strategy supported by constructivist learning theories that provide lifelong learning education contents directed to the real needs of clinical nurses and, that help overcome the constraints identified in time and cost management related with the enrolment/engagement in lifelong learning education. This strategy should be based on the state of the art, introducing approaches that increase motivation to learn and reduce the high dropout rates.

\subsection{MOOCs in nursing: the Ecare COPD training programme}

We developed a MOOC aiming at improving nursing skills to implement self-management interventions in COPD patients. This MOOC is structured on three levels. An initial level for undergraduate students, an intermediate level for general nurses and an advanced level for specialized rehabilitation nurses.

The MOOC was hosted by the Portuguese National Agency for Science and Technology (FCT) that provides an e-learning platform aiming to promote MOOCs creation and delivery by Portuguese institutions.

The underlying technology of the platform is based in OpenEDX open-source learning management system developed by MIT and Harvard and the basis for the worldwide MOOC platform edx.org. Deployed on a set of hardware located on premises, in Portugal, it relies on a hypervisor engine (XEN) and a distributed high-performance storage technology (CEPH) making it a fully open-source, high-performance infrastructure for the hosted environments and designed in three profiles: development, stage and production. All the data is stored in the environment and secured by a multi-layer service structure.

The ECare-COPD complete MOOC is organized in three levels divided into 19 learning modules, each answering to specific learning goals. Learning modules were organized in several lessons. Lessons were supported by text, multimedia, clinical virtual simulator and references. Texts supporting each lesson were differentiated by briefing focus only on the core/hot topics of the state of the art, thereby maximizing time and optimizing learning and translational potential for clinical practice. The multimedia contents focused on the major goals and topics of the training programme with an average duration of $5.06 \mathrm{~min}$ each. Overall, the Ecare-COPD MOOC is supported by 80 lessons and 106 multimedia contents. In each module, the user had access to a formative assessment with automatic feedback and guidance.

One of the most striking innovations of this MOOC is the gamification component available through an embedded clinical virtual simulator (CVS) (Body Interact ${ }^{\circledR}$ ). This MOOC provided eight clinical virtual scenarios to enhance nurses' clinical decision-making. The use of CVS allows the user to practice competencies developed over the MOOC, and the scenarios availability are progressive and dynamic throughout the learning experience.

Despite these constraints, namely the clinical challenges posed by NCDs, the need of nurses to keep up-to-date and the available ICT technologies, little is known about students and nurses easiness, usefulness and intention to use a MOOC as an educational resource.

\section{Method}

We carried out an exploratory, descriptive, transversal study to evaluate each course in terms of easiness, usefulness and intention to use the MOOC in undergraduate education and lifelong learning.

The sample was composed by three groups: second-year students of the undergraduate nursing degree course enrolled in a Nursing School in northern Portugal $(N=128)$; Portuguese Registered Nurses with experience and expertise in providing care to COPD patients $(N=15)$ and, highly skilled Portuguese Rehabilitation Specialist Nurses in COPD management $(N=18)$.

The courses were available in the MOOC hosting platform supported by the Portuguese National Agency for Science and Technology.

For data collection, a questionnaire was applied based on the Davis Technology Acceptance Model (Davis, 1989; Venkatesh and Davis, 1996) and the determinants of the ease-of-use perception of Venkatesh (2000). The Technology Acceptance Model is a theoretical model for the evaluation and use of information systems, which tests the understanding of consumer acceptance regarding the use of information technologies. In the questionnaire (Table 1 ) the three main variables of this model (ease, usefulness and intention to use) were used.

The questionnaire consisted of two sections. The first section included a brief sociodemographic characterization and the second section was composed of 12 questions (Table 1). Answers were rated on a five-point Likert scale (1-worst possible opinion, 5-best possible opinion). The validity of the content of the questionnaire was ensured by the research team, grounded on the experience and scientific publications using this methodology (Padilha et al., 2012, 2018).

The data were retrieved from the e-learning platform using its tools and processed to get a data set that could be analysed.

\subsection{Ethical considerations}

Authorization from the Ethics Committee of the applicant institution

Table 1

Questionnaire items.

\begin{tabular}{|c|c|}
\hline Item 1 & Concerning the course E-care COPD, how do you rate the ease of use \\
\hline Item 2 & $\begin{array}{l}\text { Concerning the course E-care COPD, how do you rate its usefulness for } \\
\text { your training }\end{array}$ \\
\hline Item 3 & What is your intention to use this type of course in the future \\
\hline Item 4 & What is the relevance of this course to your learning/training \\
\hline Item 5 & This course was a facilitator to your learning \\
\hline Item 6 & $\begin{array}{l}\text { Do you consider this course as a valuable contribution to your learning/ } \\
\text { training }\end{array}$ \\
\hline Item 7 & How do you rate the quality of the course \\
\hline Item 8 & How do you rate the adequacy of the course to learning/training needs \\
\hline Item 9 & How do you rate your learning/training \\
\hline $\begin{array}{r}\text { Item } \\
10\end{array}$ & What is your overall evaluation of the course \\
\hline $\begin{array}{r}\text { Item } \\
11\end{array}$ & $\begin{array}{l}\text { Do you consider this course as a differentiating contribution to the training } \\
\text { of students/nurses }\end{array}$ \\
\hline Item & Would you recommend this course to another nurse/specialist nurse \\
\hline
\end{tabular}


to complete this study was obtained (Ref.2019/1116).

\subsection{Data analysis}

First, the three groups were compared regarding age using a KruskalWallis test and the $\varepsilon^{2}$ effect measure was computed.

The content validity was guaranteed by the research team. After the data collection process, the second part of the questionnaire was submitted to evaluation on reliability through the analysis of the internal consistency using exploratory factorial analysis, Cronbach's Alpha and McDonald's Omega. The analysis was performed using jamovi v.1.0 (2019) and IBM SPSS Statistics (v.25). Results were considered significant for $p<.05$.

\section{Results}

The overall sample was comprised of 93 participants with a mean age of 25.69 years (SD \pm 9.53$)$, of which $83.9 \%(n=78)$ were female. From the total participants, $65.6 \%(n=61)$ were nursing students, $15.1 \%(n=$ 14) were Portuguese nurses and $19.4 \%(n=18)$ were Portuguese specialist rehabilitation nurses. In this study, a dropout rate of $25 \%$ was observed.

A Kruskal-Wallis test (Fig. 1) was performed to compare the age medians of the three groups. Results were significant and $69.7 \%$ of variation in this factor is explained by the grouping variable $\left(\chi^{2}(2, n=\right.$ $\left.93)=64.1, p<.001, \varepsilon^{2}=0.697\right)$. Using the Dwass-Steel-CritchlowFligner pairwise comparisons test, significant differences were found between nursing students and the other two groups (nurses, $\mathrm{p}<.001$ and rehabilitation nurses, $\mathrm{p}<.001$ ). No significant differences were found between nurses and rehabilitation nurses groups $(p=.091)$.

Table 2 displays the descriptive statistics for the 12 items regarding central tendency, dispersion and distribution shape measures. Except for item 8, all the other variables presented acceptable values for skewness and kurtosis (absolute values within the limits 3 and 8, respectively) proposed by Kline (1998).

\subsection{Exploratory Factor Analysis}

Considering this descriptive statistics results we decided not to include the item 8 in the Exploratory Factor Analysis (EFA). Items were significantly correlated (according to Bartlett's Test of Sphericity: $\chi 2$ $(55)=349, p<.001$ ) and presented good sampling adequacy (based on Kaiser-Meyer-Olkin measure $=0.1$; Sharma, 1995). Next, we performed an EFA using the Principal Axis Factoring Method to detect latent variables. The number of dimensions was decided based on the Kaiser method (eigenvalues higher than 1), Parallel Analysis and the scree plot. The two dimensions retained $53.7 \%$ of all items variance. Results were satisfactory for the two obtained components (Table 3).

The two dimensions presented average scores near the maximum scale value, the dimension 1 (F1) - Easiness and global quality of the course $(\mathrm{M}=4.70, \mathrm{SD}=0.314)$ and dimension $2(\mathrm{~F} 2)$ - Usefulness and intention to use in the future this type of course $(M=4.73, S D=0.346)$. The obtained dimensions were significantly and positively correlated $[\mathrm{r}$ (93) $=0.569, \mathrm{p}<.001]$.

Another MANOVA was performed to determine the existence of significant differences between two different groups (nursing students vs. nurses) regarding the twelve items, independently of their latent structure. Results also showed no significant differences between the two groups [Pillai's Trace $=0.199, \mathrm{~F}(12,80)=1.657, p=.093,12 \mathrm{p}=$ 0.199].

A Kruskal-Wallis test (Fig. 2) was performed to compare the three groups (nursing students: $n=61$; Nurses: $n=14$; and Rehabilitation nurses: $n=18$ ) regarding dimension 1 (F1) and dimension 2 (F2). Results were significant for dimension $1\left(\chi^{2}(2, n=93)=8.43, p=.015, \varepsilon^{2}\right.$ $=0.092)$ and non-significant for dimension $2\left(\chi^{2}(2, \mathrm{n}=93)=3.04, p=\right.$ $\left..219, \varepsilon^{2}=0.033\right)$. Using the Dwass-Steel-Critchlow-Fligner pairwise comparisons test for dimension 1 , significant differences were found between Rehabilitation nurses and the other two groups (nursing students, $p=.009$ and Nurses, $p=.010$ ). No significant differences were observed between the Nursing students and the nurses' groups ( $p=$ .484).

\section{Discussion}

This study shows that independently of age, nurses consider MOOCs useful for education and lifelong learning, expressing usefulness and intention to use this educational strategy in the future. Regarding the easiness of use and global quality of the MOOC, specialized nurses, who are older and with expertise in this field, scored higher than nurses and students. These data show that the MOOC is not only directed to younger generations but most importantly are highly beneficial to those who need access to education and lifelong learning as a way to keep up-todate.

The Ecare-COPD MOOC development was based on constructivist theories envisioning the active role of the user in the learning process with a self-paced strategy, providing an entire set of contents since the

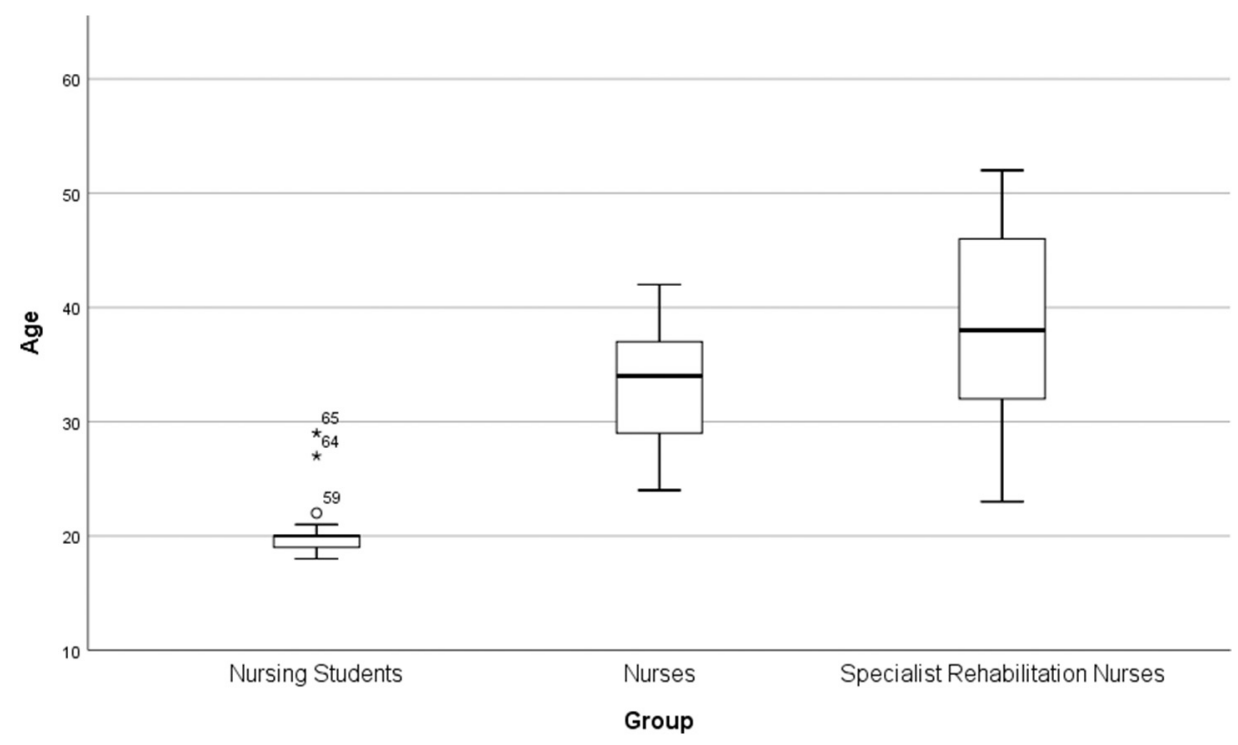

Fig. 1. A Kruskal-Wallis test to compare the three groups' age medians. 
Table 2

Descriptive statistics for the 12 items.

\begin{tabular}{|c|c|c|c|c|c|c|c|c|}
\hline Items & Minimum & Maximum & Range & Mean & Median & Std deviation & Skewness & Kurtosis \\
\hline Item 1 & 3 & 5 & 2 & 4.67 & 5.00 & 0.496 & -0.989 & -0.382 \\
\hline Item 2 & 3 & 5 & 2 & 4.80 & 5.00 & 0.431 & -1.898 & 2.712 \\
\hline Item 3 & 3 & 5 & 2 & 4.63 & 5.00 & 0.527 & -1.017 & -0.063 \\
\hline Item 4 & 3 & 5 & 2 & 4.72 & 5.00 & 0.475 & -1.306 & 0.474 \\
\hline Item 5 & 4 & 5 & 1 & 4.72 & 5.00 & 0.451 & -0.999 & -1.025 \\
\hline Item 6 & 3 & 5 & 2 & 4.77 & 5.00 & 0.445 & -1.704 & 1.885 \\
\hline Item 7 & 3 & 5 & 2 & 4.66 & 5.00 & 0.500 & -0.932 & -0.510 \\
\hline Item 8 & 1 & 5 & 4 & 4.59 & 5.00 & 0.663 & -2.286 & 8.334 \\
\hline Item 9 & 3 & 5 & 2 & 4.43 & 4.00 & 0.540 & -0.140 & -1.121 \\
\hline Item 10 & 4 & 5 & 1 & 4.67 & 5.00 & 0.474 & -0.719 & -1.516 \\
\hline Item 11 & 4 & 5 & 1 & 4.85 & 5.00 & 0.360 & -1.987 & 1.989 \\
\hline Item 12 & 4 & 5 & 1 & 4.90 & 5.00 & 0.297 & -2.773 & 5.812 \\
\hline
\end{tabular}

Table 3

Exploratory Factor Analysis (communalities and factor loadings) and reliability scores.

\begin{tabular}{llllll}
\hline & \multicolumn{2}{l}{ Communalities } & & \multicolumn{2}{l}{ Factors } \\
\cline { 2 - 3 } \cline { 5 - 6 } & Initial & Extraction & & F1 & F2 \\
\hline Item 12 & 0.510 & 0.459 & 0.714 & \\
Item 10 & 0.478 & 0.560 & 0.707 & \\
Item 11 & 0.505 & 0.511 & 0.704 & \\
Item 7 & 0.388 & 0.392 & 0.660 & \\
Item 9 & 0.345 & 0.366 & 0.533 & \\
Item 1 & 0.262 & 0.214 & 0.426 & -0.875 \\
Item 4 & 0.515 & 0.615 & & -0.706 \\
Item 6 & 0.506 & 0.607 & & -0.546 \\
Item 5 & 0.440 & 0.371 & & -0.362 \\
Item 2 & 0.459 & 0.436 & & $0.794(0.801)$ \\
Item 3 & 0.324 & 0.338 & & \\
\hline
\end{tabular}

beginning of the course and guidance in the assessment tasks. To support the user's experience we made available the highest quality information based on guidelines and experience of clinical field specialists. This is in line with Hew et al. (2020) identifying course assessment, instructor, and content as the key to users' satisfaction. The use of gamification elements with the embedded clinical virtual simulator aiming to develop clinical decision-making in nursing enhances interactivity, enjoyability, playfulness and advancement of individual clinical decision skills along the MOOC.

The ECare-COPD MOOC used strategies targeted at enhancing active learning in which the educator was simultaneously a promoter and a facilitator of the learning process, helping nurses to learn from the synthesis of the state of the art and from contextualized environments directed to meet personal expectations. In this MOOC we used text with the synthesis of the state of the art and videos that lasted on average $5.06 \mathrm{~min}$, all in line with the recommendations of Guo et al. (2014). The use of multimedia contents with the synthesis of the state of the art and the experts' vision contributes to the perception of the usefulness of the MOOC as stated by Chan et al. (2019).

The use of MOOCs developed by clinical and academic knowledge specialists to guarantee quality information, with the support of technology partners in multimedia contents production, platforms development and clinical virtual simulation, allowed to support the creation of gamified learning environments directed to enhance enjoyability, playfulness, and placing the user as an active role-player, are the key elements to make available successful MOOCs.

To enhance users' intrinsic motivation, this MOOC assembles the key elements stated by Aparicio et al. (2019) creating a MOOC that is useful,

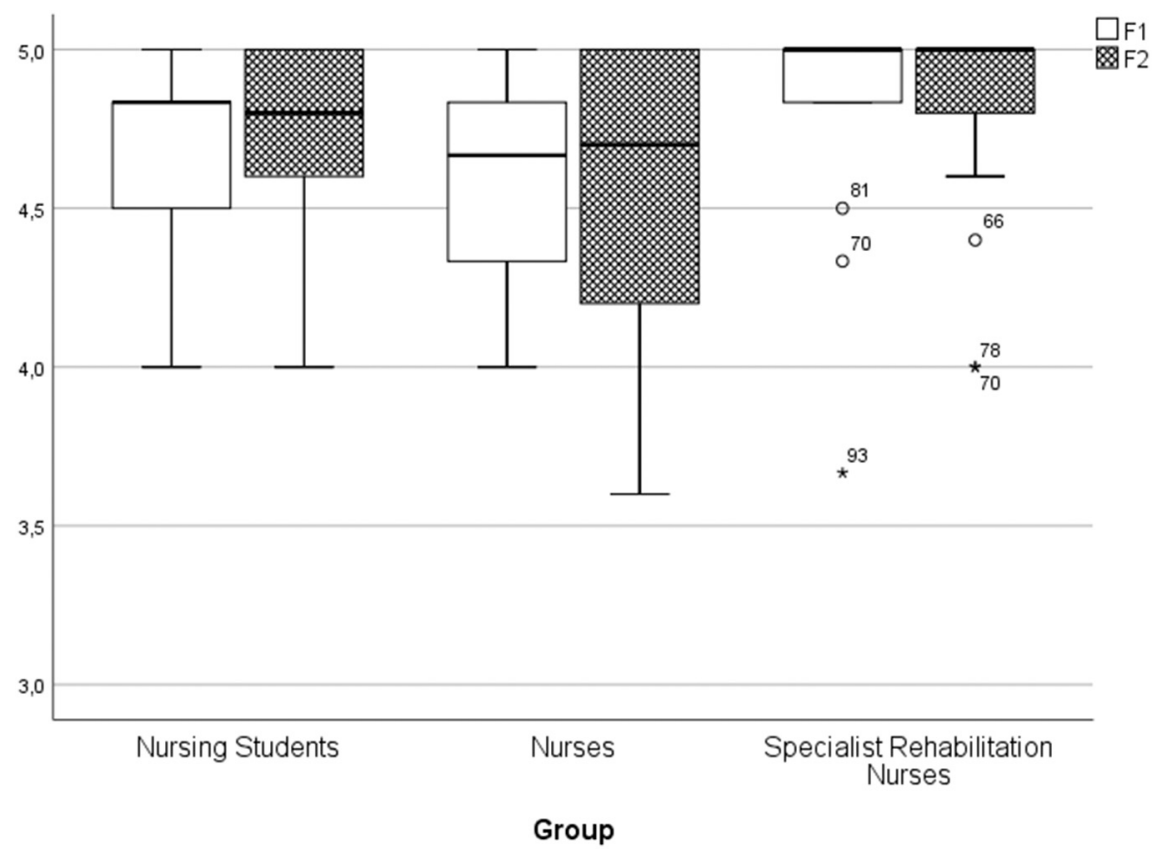

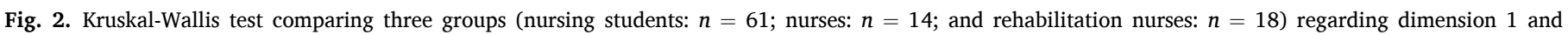
dimension 2 . 
understandable, well-structured, easy to navigate, and supported by nurses clinical needs. Reinforced by key instructional design strategies as short duration, grades attribution, and availability of certificates or badges (Khalil and Ebner, 2017). This ECare-COPD MOOC showed a dropout rate (25\%) lower than reported in other studies (Aydin, 2018; Jordan, 2014).

The use of MOOCs opens a new opportunity to bring education to nurses instead of taking nurses to schools, a circumstance that allows overcoming some of the major constraints that nurses are constantly faced with, namely keeping up-to-date in nursing and medical advancements. The availability of this new educational strategy is aligned with UN sustainable development goals three, four and nine; and with the WHO recommendations on digital interventions for health system strengthening (WHO, 2019c).

This study also shows that the use of ICT and digital platforms in nursing education open a new era in lifelong learning, bringing nurses closer to education and contributing to the safety and quality of healthcare delivered by these professionals.

Nursing tertiary education institutions based on this experience can use MOOCs as a pedagogical strategy meeting the expectations of younger generations of students, as well as the current nurses lifelong learning demands.

\section{Conclusion}

The ECare-COPD MOOC demonstrates its alignment with one of the biggest societal challenges faced by nurses: the increasing COPD prevalence and some of the major constraints of nurses to enrol in lifelong learning.

The development of this MOOC supported by clinical and academic specialist nurses and technological partners revealed to be a key factor to meet the most prominent educational demands of the nursing discipline and profession.

ECare-COPD showed usefulness and nurses' intention to use this educational strategy in future and high average rates of perceived easiness and global quality.

The MOOCs development opens a new era of opportunities for nursing education and to lifelong learning in nursing, enhancing safety and quality of the healthcare services in supporting patients to achieve a better quality of life.

\section{Funding/support}

This article was supported by FEDER through the operation POCI-010145-FEDER-023342 funded by the Programa Operacional Competitividade e Internacionalização - COMPETE2020 and by Portuguese National Funds through FCT - Fundação para a Ciência e a Tecnologia.

\section{Declaration of competing interest}

The authors declare that they have no known competing financial interests or personal relationships that could have appeared to influence the work reported in this paper

\section{References}

Albelbisi, N.A., 2019. The role of quality factors in supporting self-regulated learning (SRL) skills in MOOC environment. Educ. Inf. Technol. 24, 1681-1698. https://doi. $\operatorname{org} / 10.1007 /$ s10639-018-09855-2.

AlRuthia, Y., Alhawas, S., Alodaibi, F., et al., 2019. The use of active learning strategies in healthcare colleges in the Middle East. BMC Medical Education 19, 143. https:// doi.org/10.1186/s12909-019-1580-4.

Aparicio, M., Oliveira, T., Bacao, F., et al., 2019. Gamification: a key determinant of Massive Open Online Course (MOOC) success. Inf. Manag. 56 (1), 39-54. https:// doi.org/10.1016/j.im.2018.06.003.

Aydin, C.H., 2018. MOOCs as change agents. In: Jansen, D., Konings, L. (Eds.), The 2018 OpenupEd Trend Report on MOOCs. EADTU, Maastricht, NL, pp. 18-21.

Berman, A.H., Biguet, G., Stathakarou, N., et al., 2017. Virtual patients in a behavioral medicine Massive Open Online Course (MOOC): a qualitative and quantitative analysis of participants' perceptions. Acad. Psychiatry 41 (5), 631-641. https://doi. org/10.1007/s40596-017-0706-4.

Buckley, P., Doyle, E., 2014. Gamification and student motivation. Interact. Learn. Environ. 24 (6), 1162-1175. https://doi.org/10.1080/10494820.2014.964263.

Chan, M., Barchino, R., Medina-Merodio, R., et al., 2019. MOOCs, an innovative alternative to teach first aid and emergency treatment: a practical study. Nurse Educ. Today 79, 92-97. https://doi.org/10.1016/j.nedt.2019.05.008.

Chau, M., Wong, A., Wang, M., et al., 2013. Using 3D virtual environments to facilitate students in constructivist learning. Decis. Support. Syst. 56, 115-121. DOI. htt ps://doi.org/10.1016/j.dss.2013.05.009.

Cormier, D., 2008. The CCK08 MOOC-Connectivism Course, 1/4 Way, Dave's Educational Blog, p. 2.

Davis, F.D., 1989. Perceived usefulness, perceived ease of use, and user acceptance of information technology. MIS Q. 13 (3), 319-340.

Gentry, S., L'Estrade Ehrstrom, B., Gauthier, A., et al., 2018. Serious gaming and gamification interventions for health professional education. Cochrane Database Syst. Rev. 6, CD012209 https://doi.org/10.1002/14651858.CD012209.pub2.

GOLD - Global Initiative for Chronic Obstructive Lung Disease, 2020. Global Strategy for the Diagnosis, Management, and Prevention of Chronic Obstructive Pulmonary Disease. GOLD, Fontana, US.

Guillén-Nieto, V., Aleson-Carbonell, M., 2012. Serious games and learning effectiveness: the case of it's a deal! Comput. Educ. 58 (1), 435-448. https://doi.org/10.1016/j. compedu.2011.07.015.

Guo, P.J., Kim, J., Rubin, R., 2014. How video production affects student engagement: an empirical study of MOOC videos. In: Proceedings of the First ACM Conference on Learning @ Scale Conference (L@S '14). Association for Computing Machinery, New York, US, pp. 41-50. https://doi.org/10.1145/2556325.2566239.

Hew, F.K., Hu, X., Quiao, C., et al., 2020. What predicts student satisfaction with MOOCs: a gradient boosting trees supervised machine learning and sentiment analysis approach. Comput. Educ. 145, 103724 https://doi.org/10.1016/j. compedu.2019.103724.

Hoke, M., Robbins, L., 2005. The impact of active learning on nursing students' clinical success. J. Holist. Nurs. 23 (3), 348-355. https://doi.org/10.1177/ 0898010105277648.

Jordan, K., 2014. Initial trends in enrolment and completion of massive open online courses. The International Review of Research in Open and Distributed Learning 15 (1). https://doi.org/10.19173/irrodl.v15i1.1651.

Khalil, M., Ebner, M., 2017. Clustering patterns of engagement in Massive Open Online Courses (MOOCs): the use of learning analytics to reveal student categories. J. Comput. High. Educ. 24, 114-132. https://doi.org/10.1007/s12528-016-9126-9.

Khalil, M., Wong, J., de Koning, B., et al., 2018. Gamification in MOOCs: a review of the state of the art. In: 2018 IEEE Global Engineering Education Conference (EDUCON), Tenerife, SP, pp. 1629-1638.

Kline, R., 1998. Principles and Practice of Structural Equation Modeling. Guilford, New York, US.

Lahti, M., Hätönen, H., Välimäki, M., 2014. Impact of e-learning on nurses' and student nurses knowledge, skills, and satisfaction: a systematic review and meta-analysis. Int. J. Nurs. Stud. 51 (1), 136-149. https://doi.org/10.1016/j.ijnurstu.2012.12.017.

Looyestyn, J., Kernot, J., Boshoff, K., et al., 2017. Does gamification increase engagement with online programs? A systematic review. PLoS One 12 (3), e0173403. https://doi. org/10.1371/journal.pone.0173403.

Marques, D., 2018. Virtual Immersive Simulation in Lifelong Education in Nursing [dissertation]. Nursing School of Porto, Porto, PT.

Padilha, J.M., Sousa, P., Pereira, F., 2012. Analysis of use of technological support and information content by patients with chronic obstructive pulmonary disease. Acta Paulista de Enfermagem 25 (spe1), 60-66. https://doi.org/10.1590/S010321002012000800010.

Padilha, J.M., 2013. Promotion of self-management in patients with COPD: a course of action-research. Thesis of candidature for the degree of Doctor in nursing, presented to the Portuguese Catholic University (in Portuguese). http://hdl.handle.net/10400 $.14 / 14958$.

Padilha, J.M., Machado, P.P., Ribeiro, A.L., et al., 2018. Clinical virtual simulation in nursing education. Clinical Simulation in Nursing 15 (C), 13-18. https://doi.org/ 10.1016/j.ecns.2017.09.005.

Padilha, J.M., Machado, P.P., Ribeiro, A., et al., 2019. Clinical virtual simulation in nursing education: randomized controlled trial. J. Med. Internet Res. 21 (3), e11529 https://doi.org/10.2196/11529.

Rosa, J., 2018. Virtual Immersive Simulation in Lifelong Education in Nursing [dissertation]. Nursing School of Porto, Porto, PT.

Scott, F., Sarah, L., Eddy, M., et al., 2014. Active learning increases student performance in science, engineering, and mathematics. PNAS - Proceedings of the National Academy of Sciences of the USA 111 (23), 8410-8415. https://doi.org/10.1073/ pnas.1319030111.

Sharma, S., 1995. Applied multivariate techniques. John Wiley \& Sons, Inc., USA.

The Jamovi Project, 2019. jamovi (Version 1.0) [Computer Software]. Retrieved February 27, 2020 from. https://www.jamovi.org.

United Nations, 2015. Transforming our world: the 2030 agenda for sustainable development. A/RES/70/1. Retrieved March 27, 2020 from. https://sustainabled evelopment.un.org/post2015/transformingourworld/publication.

Vaona, A., Banzi, R., Kwag, K.H., et al., 2018. E-learning for health professionals. Cochrane Database Syst. Rev. 1, CD011736 https://doi.org/10.1002/14651858. CD011736.pub2.

Venkatesh, V., 2000. Determinants of perceived ease of use: integrating control, intrinsic motivation, and emotion into in the technology acceptance model. Inf. Syst. Res. 11 (4), 342-365. 
Venkatesh, V., Davis, F.D., 1996. A model of the antecedents of perceived ease of use: development and test. Decis. Sci. 27, 451-481. https://doi.org/10.1111/j.15405915.1996.tb01822.x.

Voutilainen, A., Saaranen, T., Sormunen, M., 2017. Conventional vs. e-learning in nursing education: a systematic review and meta-analysis. Nurse Educ. Today 50, 97-103. https://doi.org/10.1016/j.nedt.2016.12.020.

Woods, M., Rosenberg, M.E., 2016. Educational tools: thinking outside the box. Clin. J. Am. Soc. Nephrol. 11 (3), 518-526. https://doi.org/10.2215/CJN.02570315.

World Health Organization, 2019a. Noncommunicable diseases and their risk factors. Major NCDs and their risk factors. Retrieved December 26, 2019. https://www.who int/ncds/introduction/en/.
World Health Organization, 2019b. Noncommunicable diseases. Retrieved December 26, 2019. http://www euro who.int/en/health-topics/noncommunicable-diseases. World Health Organization, 2019c. WHO Guideline: Recommendations on Digital Interventions for Health System Strengthening. World Health Organization, Geneva, $\mathrm{CH}$.

Yang, M., Shao, Z., Liu, Q., et al., 2017. Understanding the quality factors that influence the continuance intention of students toward participation in MOOCs. Educ. Technol. Res. Dev. 65, 1195-1214. https://doi.org/10.1007/s11423-017-9513-6.

Zwerink, M., Brusse-Keizer, M., van der Valk, P., et al., 2014. Self management for patients with chronic obstructive pulmonary disease. Cochrane Database Syst. Rev. 3, CD002990. 